\title{
CRESCIMENTO E DESENVOLVIMENTO RADICULAR DO PORTA-ENXERTO DE MACIEIRA MARUBAKAIDO (Malus prunifolia) MICROPROPAGADO SUB- METIDO À INOCULAÇÃO MICORRÍzICA E À PODA DE RAÍZES ${ }^{1}$
}

\author{
LUCIR MARIA LOCATELLI², PAULO EMÍLIO LOVATO³, ENIO LUIZ PEDROTTI ${ }^{4}$
}

\begin{abstract}
RESUMO - Com o objetivo de avaliar os efeitos da inoculação micorrízica e da poda de raízes sobre a parte aérea e sistema radicular do porta-enxerto Marubakaido, obtido in vitro, foi conduzido um estudo em câmara de crescimento. A base das plantas micropropagadas foi imersa em ácido indolbutírico e transferida para substrato à base de solo, a fim de ser enraizada ex vitro. Antes ou após a fase de enraizamento (21 dias), inoculou-se uma mistura de isolados de fungos micorrízicos arbusculares, e um terço das plantas sofreu poda de raízes. Após 51 dias, avaliaram-se colonização micorrízica, altura, massa da parte aérea e raízes, e número e comprimento de raízes de diferentes ordens. A porcentagem de colonização radicular foi maior no tratamento inoculado antes do enraizamento, que também teve os maiores valores de incremento em altura e de produção de biomassa da parte aérea. A poda de raízes causou reduções significativas na colonização micorrízica, no crescimento da parte aérea e no desenvolvimento radicular. O comprimento e a ramificação das raízes foram aumentados pela micorrização e diminuídos pela poda. Em conclusão, a poda de raízes é prejudicial e a inoculação micorrízica, antes do enraizamento, é benéfica para a produção de mudas micropropagadas do porta-enxerto Marubakaido.
\end{abstract}

Termos de indexação: arquitetura radicular, época de inoculação, Glomus sp, Scutellospora sp

\section{SHOOT AND ROOT GROWTH OF MICROPROPAGATED MARUBAKAIDO APPLE (Malus prunifolia) ROOTSTOCK INOCULATED WITH ARBUSCULAR MYCORRHIZAL FUNGI AND SUBJECT TO ROOT PRUNING}

\begin{abstract}
The effects of mycorrhizal inoculation and root pruning on shoot and root growth by the Marubakaido apple rootstock were evaluated in a growth chamber study. The micropropagated plantlets were dipped in indole-butyric acid and transferred to a soilbased substrate, in order to develop ex-vitro rooting. The plants were inoculated with mycorrhizal fungi before and after a 21-day weaning period, when a root pruning treatment was applied as well. After 51 days, mycorrhizal colonization, shoot length, root and shoot mass and root length and number were assessed. The plants inoculated before weaning had higher root colonization and enhanced shoot mass, in comparison to the plants inoculated after that period. The root pruning significantly reduced the mycorrhizal colonization, shoot mass and root growth. The root number and length were enhanced by mycorrhizal colonization and reduced by pruning. The results indicate that the production of micropropagated Marubakaido rootstocks were benefits from mycorrhizal inoculation and it is damaged by the root pruning.
\end{abstract}

Index terms: root architecture, inoculation period, Glomus sp, Scutellospora sp

\section{INTRODUÇÃo}

A produção de plantas pode ser beneficiada pela obtenção rápida de mudas de alta qualidade e homogeneidade, proporcionada pela micropropagação. Esta técnica elimina microrganismos patogênicos, mas também exclui organismos que podem favorecer o estabelecimento das mudas micropropagadas e seu crescimento após o transplantio (Granger et al.,1983), como os fungos que formam as micorrizas. Essas associações mutualísticas, envolvendo fungos do solo e as raízes da maioria das plantas, constituem uma importante ligação entre os componentes bióticos e abióticos do solo, e desempenham papel fundamental na sobrevivência, no crescimento e no desenvolvi- mento das plantas. As micorrizas têm efeito positivo no crescimento das plantas, pela melhoria na absorção de nutrientes, especialmente o fósforo, e pelo aumento da tolerância a estresses bióticos e abióticos (Saggin \& Lovato,1999).

Entre as espécies lenhosas micropropagadas, a macieira é considerada de difícil enraizamento, característica associada a baixas taxas de sobrevivência em condições ex vitro. Para superar tais problemas, é adotada a técnica de submeter a planta, simultaneamente, ao enraizamento e à aclimatização. No momento de saída das condições in vitro, as plantas micropropagadas são mais suscetíveis a estresses ambientais, devido ao fraco desenvolvimento do sistema radicular, à formação incompleta dos estômatos e ao desenvolvimento incipiente da cutícula das

1 (Trabalho 162/2001). Recebido: 08/10/2001. Aceito para publicação: 15/03/2002. Extraído da Dissertação de Mestrado, apresentada pela primeira autora à UFSC-SC, Florianópolis, SC. Financiado pela CAPES, CNPq e FINEP.

2 Biól, Mestre em Biotecnologia, Dep. de Engenharia Rural, Centro de Ciências Agrárias, Universidade Federal de Santa Catarina, Caixa Postal 476, 88040-970 Florianópolis, SC Email: lucir@mbox1.ufsc.br

3 Engo Agro , Dr., Prof. Adjunto, Dep. De Engenharia Rural, Centro de Ciências Agrárias, Universidade Federal de Santa Catarina, Caixa Postal 476, 88040-970 Florianópolis, SC. Email: plovato@mbox1.ufsc.br

4 Engo Agrọ , Dr., Prof. Adjunto, Dep. de Fitotecnia, Centro de Ciências Agrárias, Universidade Federal de Santa Catarina, Caixa Postal 476, 88040970 Florianópolis, SC. Email: pedrotti@cca.ufsc.br 
folhas (Hooker et al.,1994). Quando as plantas são enraizadas in vitro, as zonas de transição entre as raízes e a parte aérea podem ser anormais (Grout \& Aston,1977), e as conexões vasculares são por vezes incompletas, restringindo a passagem da água absorvida pelas raízes. As raízes que crescem in vitro, perdem os pêlos radiculares e podem morrer quando transferidas para o substrato (Debergh \& Maene,1981). Por essas razões, é crescente a adoção do enraizamento ex vitro ou a poda às raízes na saída das condições in vitro. No entanto, a remoção parcial ou total do sistema radicular pode ter diferentes efeitos sobre as plantas, e é preciso conhecer o comportamento de diferentes genótipos. Este trabalho teve por objetivo avaliar os efeitos da inoculação com fungos micorrízicos e da poda de raízes sobre o crescimento do porta-enxerto Marubakaido e sobre seu desenvolvimento radicular.

\section{MATERIAL E MÉTODOS}

Para a produção das mudas do porta-enxerto Marubakaido - Malus prunifolia (Willd. Borkh) - bases de brotações oriundas de multiplicação in vitro, com 4-5 pares de folhas e 3-4 cm de altura, foram imersas em solução $5 \mathrm{mM}$ de ácido indolibutírico por 20s e transferidas para aclimatização (Nunes et al., 1999). O experimento (fatorial $2 \times 2 \times 2$ ) foi composto de tratamentos de inoculação (inoculação micorrízica e não micorrízica), épocas de inoculação (antes e após a fase de enraizamento), com ou sem poda de raízes. Utilizou-se um delineamento completamente casualizado, com 12 repetições, os dados foram submetidos à análise de variância, (programa StatGraphics, versão 7.0) e as médias foram comparadas pelo teste de Newman-Keuls, $\mathrm{p} £ 0,05$. Cada planta recebeu $1,0 \mathrm{~g}$ de inóculo micorrízico, constituído de uma mistura de Scutellospora pellucida (isolado no 2, coleção da UFSC), Glomus sp. (isolado nํ 35), G. etunicatum (isolado noㅜ 6) e G. etunicatum (isolado $\mathrm{n}^{-}$8), multiplicados em vasos com Paspalum notatum var. saurae ou Tagetes erecta. A microbiota não micorrízica do solo foi obtida através da suspensão de $100 \mathrm{~g}$ do inóculo em $1 \mathrm{~L}$ de água destilada. Após agitação intensa, a suspensão foi passada em papel filtro (abertura de $50 \mathrm{~mm}$ ) e adicionou-se $1 \mathrm{~mL}$ do filtrado a cada planta nos tratamentos não micorrizados. O substrato utilizado foi uma mistura de Nitossolo Vermelho Distroférrico, composto termofílico e areia (1:1:1; v:v:v), desinfestado por 10 minutos em forno de microondas (National NE 7770KK, 2450 Mhz, 1420W) e distribuído em bandejas com alvéolos de $120 \mathrm{~cm}^{3}$. As plantas foram transferidas para as bandejas e aclimatizadas simultaneamente à formação de raízes, sob alta umidade relativa do ar $(\sim 100 \%)$, temperatura de $21^{\circ} \mathrm{C} \pm 3$, fotoperíodo de 16 horas e intensidade de radiação fotossinteticamente ativa (RFA) de $73 \mu \mathrm{mol} \mathrm{m}^{-2} \mathrm{~s}^{-1}$. Após 21 dias, fez-se a poda de raízes, sendo que as plantas submetidas a esse tratamento foram recolocadas em bandejas alveoladas. O experimento foi conduzido em câmara de crescimento, a $21^{\circ} \mathrm{C} \pm 3$, fotoperíodo de 16 horas e RFA de $120 \mu \mathrm{mol} \mathrm{m} \mathrm{m}^{-2} \mathrm{~s}^{-1}$. Todas as plantas receberam água diariamente e, semanalmente, aplicou-se $1 \mathrm{~mL}$ de solução nutritiva de Long Ashton (Resh, 1997) com 10\% da concentração original de fósforo. A fim de calcular o incremento em altura das plantas, medições desta variável foram realizadas ao final do enraizamento e no momento da coleta. Aos 51 dias após a saída in vitro das plantas, foram determinados peso da matéria fresca das raízes, peso de matéria seca da parte aérea e colonização micorrízica, e fez-se a análise do desenvolvimento do sistema radicular. O número e o comprimento das raízes foram avaliados pela técnica da grade quadriculada. As raízes foram cortadas e separadas em placas de Petri conforme a ordem à qual pertenciam (eixos radiculares, ordem 1 , ordem 2 , ordem 3 e ordem 4), contando-se o número de pontos de interseção $(\mathrm{N})$ entre as raízes e as linhas verticais e horizontais da grade no fundo da placa. O comprimento do sistema radicular ( $\mathrm{R})$ da amostra foi calculado de acordo com a técnica de Tennant (1975). A fórmula utilizada foi: $\mathrm{R}=\mathrm{N}$ x Fator de Conversão (0,7857). A intensidade de colonização micorrízica foi avaliada pela técnica de Trouvelot et al. (1986), após descoloração das raízes em KOH 10\% e coloração com Azul de Tripano em glicerol acidificado (Koske \& Gemma,1989).

\section{RESULTADOS E DISCUSSÃO}

A porcentagem de colonização radicular foi significativamente maior no tratamento inoculado em estágio inicial do enraizamento que nos tratamentos que receberam inoculação após o enraizamento, e as plantas que sofreram poda de raízes apresentaram os menores índices de colonização (Tabela 1). Esse índices estiveram associados a aumentos no crescimento das plantas, confirmando o potencial de inoculação micorrízica (Uosukainen \& Vesteberg, 1994; Locatelli e Lovato, 2001), e os maiores valores de incremento em altura e de produção de biomassa da parte aérea ocorreram quando a inoculação com os FMAs ocorreu antes do enraizamento. A inoculação após o enraizamento também proporcionou um acréscimo em altura e biomassa das plantas, quando comparadas com plantas não inoculadas, mas o efeito foi menor que o verificado em plantas inoculadas antes do enraizamento. Os dados confirmam que a introdução de FMA, mesmo após a fase de enraizamento, tem um grande potencial nos programas de produção de mudas micropropagadas. Os aumentos do crescimento do porta-enxerto Marubakaido estão de acordo com trabalhos sobre micorrização de plantas micropropagadas (Saggin \& Lovato,1999).

A poda de raízes teve efeitos marcantes sobre o crescimento das plantas, levando a reduções significativas de incremento em altura e peso de matéria seca da parte aérea (Tabela 1), seja nos tratamentos que receberam o inóculo micorrízico, seja naqueles que receberam somente a biota não micorrízica do solo. A redução da massa de raízes, determinada pela poda, levou a planta a mudar sua estratégia no acúmulo de biomassa, para manter o equilíbrio entre a parte aérea e o sistema radicular, como preconizado por Hartmann et al. (1997). Além disso, pode ser mais importante para a planta restabelecer o sistema radicular eliminado pela poda do que acumular reservas na parte aérea, visto que um volume maior de raízes é determinante no processo de retomada de crescimento das plantas após a passagem para a aclimatização (Ziv, 1995). No presente trabalho, a redução do volume de raízes determinou um menor acúmulo de biomassa na parte aérea, por ter diminuído a eficiência na captação de água e de nutrientes importantes para o crescimento inicial da planta, como observado por Wraigth e Wraigth (1998).

A época de introdução dos FMAs e da biota não micorrízica do solo não teve efeito significativo sobre o acúmulo 
de biomassa das raízes. No entanto, as plantas que receberam os inoculantes contendo FMA antes da fase de enraizamento, tenderam a apresentar massa da matéria fresca de raízes maior que plantas que receberam os inóculos após a fase de enraizamento. Isso indica que a produção de biomassa radicular esteve relacionada não somente à presença de FMA, mas também à ação de outros microrganismos presentes no substrato ou na rizosfera. É preciso considerar, porém, que a biomassa não é o melhor parâmetro para indicar a eficiência das raízes, o que exige que se conheça seu desenvolvimento, expresso pela arquitetura do sistema radicular (Hetrick,1991).

O desenvolvimento do sistema radicular do porta-enxerto Marubakaido, avaliado através do número e do comprimento totais de raízes (Tabela 2), foi mais afetado pela poda que pela inoculação micorrízica. Os dois tratamentos que tiveram poda de raízes - com inoculação micorrízica ou com adição somente de

TABELA 1 - Intensidade da colonização micorrízica (MIC), incremento em altura (H), peso de matéria seca de parte aérea (MSA) e peso da matéria fresca de raízes (MFR) de mudas micropropagadas do porta-enxerto Marubakaido, submetidas ou não à poda de raízes, com inoculação de fungos micorrízicos arbusculares ou da biota não micorrízica, antes ou depois da fase de enraizamento das plantas. Valores coletados 51 dias após a saída das condições in vitro.

\begin{tabular}{|c|c|c|c|c|c|c|}
\hline \multicolumn{3}{|c|}{ Tratamentos } & \multirow{2}{*}{$\begin{array}{c}\text { MI C } \\
(\%)\end{array}$} & \multirow{2}{*}{$\frac{\mathrm{H}}{\mathrm{cm} \mathrm{planta}}$} & \multirow{2}{*}{$\begin{array}{c}\text { MSA } \\
\text { g planta }^{-1}\end{array}$} & \multirow{2}{*}{$\begin{array}{c}\text { MFR } \\
\mathrm{cm} \text { planta }^{-1}\end{array}$} \\
\hline Poda & Micorrização & Época de Inoculação & & & & \\
\hline Não & Sim & Antes & $51,3 \mathrm{a}$ & $12,5 \mathrm{a}$ & $0,522^{a}$ & $0,463 \mathrm{a}$ \\
\hline Não & $\operatorname{Sim}$ & Depois & $36,4 b$ & $9,7 b$ & $0,392 b$ & $0,399 \mathrm{ab}$ \\
\hline Sim & Sim & Depois & $22,8 \mathrm{c}$ & $7,2 \mathrm{c}$ & $0,252 \mathrm{~cd}$ & $0,254 \mathrm{bc}$ \\
\hline Não & Não & Antes & $0,0 \mathrm{~d}$ & $6,8 \mathrm{c}$ & $0,333 \mathrm{bc}$ & $0,495 \mathrm{a}$ \\
\hline Não & Não & Depois & $0,0 \mathrm{~d}$ & $5,0 \mathrm{~cd}$ & $0,266 \mathrm{~cd}$ & $0,381 \mathrm{ab}$ \\
\hline Sim & Não & Depois & $0,0 \mathrm{~d}$ & $3,5 \mathrm{~d}$ & $0,166 \mathrm{~d}$ & $0,299 \mathrm{bc}$ \\
\hline
\end{tabular}

Valores seguidos de mesma letra, em cada coluna, não diferem significativamente entre si (Teste de Newman-Keuls, $\mathrm{p} \leq 0,05)(\mathrm{n}=12)$.

TABELA 2 - Número e comprimento de eixos radiculares e raízes de ordens 1; 2 e 3 e total de mudas micropropagadas do porta-enxerto Marubakaido, submetidas ou não à poda de raízes, com inoculação de fungos micorrízicos arbusculares ou da biota não micorrízica, antes ou depois da fase de enraizamento das plantas. Valores coletados 51 dias após a saída das condições in vitro.

\begin{tabular}{|c|c|c|c|c|c|c|c|}
\hline \multicolumn{8}{|c|}{ Eixos } \\
\hline \multicolumn{3}{|c|}{ Tratamentos } & Radiculares & Ordem 1 & Ordem 2 & Ordem 3 & Total \\
\hline \multicolumn{8}{|c|}{ Época de } \\
\hline Poda & Micorrização & Inoculação & 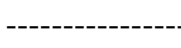 & -------- & ero ------- & ----- & --- \\
\hline Não & Sim & Antes & $22 \mathrm{ab}$ & $423 a$ & $285 \mathrm{ab}$ & $10 \mathrm{~b}$ & $740 \mathrm{a}$ \\
\hline Não & Sim & Depois & $27 \mathrm{a}$ & $400 \mathrm{a}$ & $314 a b$ & $16 b$ & $758 \mathrm{a}$ \\
\hline Sim & Sim & Depois & $24 \mathrm{ab}$ & $243 b c$ & $173 \mathrm{c}$ & $11 b$ & $452 \mathrm{bc}$ \\
\hline Não & Não & Antes & $17 \mathrm{ab}$ & $381 \mathrm{a}$ & $371 \mathrm{a}$ & $34 \mathrm{a}$ & $802 \mathrm{a}$ \\
\hline Não & Não & Depois & $18 \mathrm{ab}$ & $32 \mathrm{ab}$ & $212 b c$ & $10 \mathrm{~b}$ & $561 \mathrm{ab}$ \\
\hline Sim & Não & Depois & $15 b$ & $164 \mathrm{c}$ & $129 \mathrm{c}$ & $19 b$ & $327 \mathrm{c}$ \\
\hline Não & Sim & Antes & $90 \mathrm{ab}$ & $366 a$ & $169 b$ & $5 b$ & $630 a b$ \\
\hline Não & Sim & Depois & $107 \mathrm{a}$ & $340 \mathrm{a}$ & $167 b$ & $7 b$ & $621 a b$ \\
\hline Sim & Sim & Depois & $64 b c$ & $211 b$ & $102 b$ & $6 b$ & $383 \mathrm{~cd}$ \\
\hline Não & Não & Antes & $86 a b$ & $442 \mathrm{a}$ & $262 a$ & $20 \mathrm{a}$ & $810 \mathrm{a}$ \\
\hline Não & Não & Depois & $74 a b c$ & $322 a$ & $133 b$ & $6 b$ & $535 \mathrm{bc}$ \\
\hline Sim & Não & Depois & $47 c$ & $154 b$ & $92 b$ & $11 \mathrm{~b}$ & $304 d$ \\
\hline
\end{tabular}

Valores seguidos de mesma letra, em cada coluna, não diferem significativamente entre si $($ Teste de Newman-Keuls, $\mathrm{p} \leq 0,05)(\mathrm{n}=12)$. 
biota não micorrízica do solo - apresentaram uma redução de cerca de $40 \%$ no número e comprimento totais de raízes, quando comparados aos tratamentos que não foram submetidos a tal procedimento. A redução no número total foi composta pela diminuição no número de raízes de ordem 1 e ordem 2 , enquanto, no comprimento, a redução ocorreu nos eixos radiculares e nas raízes de ordem 1 . No que se refere ao número e comprimento de raízes nas diferentes ordens, a comparação de plantas micorrizadas e não micorrizadas mostra que, dentro de cada combinação dos outros fatores, as plantas com micorrizas tenderam a apresentar médias superiores no número de eixos radiculares e de raízes de ordem 1. Mesmo que as diferenças não tenham sido significativas pela análise estatística, a repetição do comportamento, nessas duas variáveis, sugere um efeito da simbiose, sobre a arquitetura radicular, como constatado em plantas lenhosas por Tisserant et al. (1996). A época de introdução dos FMAs no sistema não proporcionou diferenças no número ou no comprimento total de raízes. O tratamento sem poda de raízes e com adição da biota não micorrízica do solo, antes da fase de enraizamento, teve plantas com número e comprimento totais de raízes equivalentes aos dos tratamentos que receberam inóculo micorrízico. No entanto, aquele tratamento apresentou os maiores valores de número e comprimento de raízes de ordem 2 e ordem 3, o que evidencia que a biota não micorrízica do solo teve um efeito sobre o desenvolvimento do sistema radicular do porta-enxerto utilizado.

Os resultados indicam, portanto, que, para o porta-enxerto Marubakaido, a poda de raízes é uma prática nociva e não deve ser utilizada. Isso está em desacordo com trabalhos que recomendam a remoção parcial ou total das raízes produzidas in vitro, porque tal procedimento resultaria em melhor formação de raízes adventícias e plantas mais uniformes (Thomas \& Ravindra,1997). O efeito negativo da poda sobre o crescimento e a arquitetura radicular do porta-enxerto Marubakaido, observado por Fráguas et al. (1997), foi confirmado por este trabalho, que demonstrou também efeitos dos fungos micorrízicos arbusculares, e mesmo da biota não micorrízica do solo, sobre tais variáveis.

\section{CONCLUSÕES}

A poda de raízes é prejudicial e a inoculação micorrízica, no início do período de aclimatização e enraizamento, é benéfica para a produção de mudas micropropagadas do porta-enxerto Marubakaido.

\section{REFERÊNCIAS BIBLIOGRÁFICAS}

DEBERGH, P.C.; MAENE, L.J. A scheme for commercial propagation of ornamental plants by tissue-culture. Scientia Horticulturae, Amsterdam, v.14, n.4, p.335-345, 1981.

FRÁGUAS , C.B., HOFFMANN, A., PASQUAL, M. CHALFUN, N.N.J. Efeitos da pré-aclimatização e da poda de raízes na sobrevivência e crescimento de mudas micropropagadas de macieira 'Marubakaido'. In: ENCONTRO BRASILEIRO DE BIOTECNOLOGIA VEGETAL, 2., 1997, Gramado. Programas e
Resumos. Gramado: FAO, 1997.p.24.

GRANGER, R.L.; PLENCHETTE, C.; FORTIN, J.A. Effect of a vesicular arbuscular (VA) endomycorrhizal fungus (Glomus epigaeum) on the growth and leaf mineral-content of 2 apple clones propagated in vitro. Canadian Journal of Plant Science, Ottawa, n.63, n.2, p.551-555, 1983.

GROUT, B.W.W.; ASTON, M.J. Transplanting of cauliflower plants regenerated from meristem culture .1. water-loss and water transfer related to changes in leaf wax and to xylem regeneration. Horticulture Research, Edinburgh. v.17, n.1, p.1-7, 1977

HARTMANN, H.T.; KESTER, D.E.; DAVIES Jr., F.T.; GENEVE, R.L. Plant Propagation: principles and practices. 6. ed. Singapore: Prentice-Hall, 1997. 770p.

HETRICK, B. A. D. Mycorrhizas and Root Architecture. Experientia, Basel, v.47, p.355-362. 1991.

HOOKER, J. E.; GIANINAZZI, S.; VESTBERG, M.; BAREA, J. M.; ATKINSON, D. The application of arbuscular mycorrhizal fungi to micropropagation systems - an opportunity to reduce chemical inputs. Agricultural Science in Finland, Helsinki, v.3, n.3, p.227-232, 1994.

KOSKE, R.E.; GEMMA, J.N.A modified procedure for staining roots to detect VA mycorrhizas. Mycological Research, Cambridge, v.92, n.4, p.486-505, 1989.

LOCATELLI, L.M.; LOVATO, P.E. Inoculação micorrízica e aclimatização de dois porta-enxertos de macieira (Malus spp.) micropropagados. Pesquisa Agropecuária Brasileira, Brasília, (no prelo).

NUNES, J.C.O.; BARPP, A.; SILVA, F.C.; PEDROTTI, E.L. Micropropagação do porta-enxerto 'Marubakaido' (Malus prunifolia), a partir da cultura de meristemas. Revista Brasileira de Fruticultura, Jaboticabal, v.21, n.2, p.191-195, 1999.

RESH, H.M Cultivos Hidroponicos - Nuevas tecnicas de producción. 4.ed. Editora Mundi - Prensa Libros S.A., 1997, 509p.

SAGGIN JR.; LOVATO, P.E. Aplicação de micorrizas arbusculares: mudas e plantas micropropagadas. In: SIQUEIRA, J.O.; MOREIRA, F.M.S.; LOPES, A.S.; GUILHERME, L.R.G.; FAQUIN,V.; FURTINI NETO, A.E.; CARVALHO, J.G. Interrelações biologia-fertilidade do solo. Viçosa: Sociedade Brasileira de Ciência do Solo, 1999. p.725-773.

TENNANT, D. A test of a modified line intersection method of measuring root length. Journal of Ecology, Oxford, v.63, p.995$1001,1975$.

THOMAS, P.; RAVINDRA, M.B. Effects of pruning or removal of in vitro formed roots on ex vitro regeneration and growth in micropropagated grapes. Plant Cell Tissue and Organ Culture, Dordrecht, v.51, n.3, p.177-180, 1997. 
TISSERANT, B.; GIANINAZZI, S.; GIANINAZZI-PEARSON, V. Relationships between lateral root order, arbuscular mycorrhiza development, and the physiological state of the symbiotic fungus in Platanus acerifolia. Canadian Journal Botanical, Ottawa, v.74, n 12, p.1947-1955, 1996.

TROUVELOT, A.; KOUGH, J.L.; GIANINAZZI-PEARSON, V. Mesure du taux de mycorhization VA d'un sisteme radiculare. Recherche de méthodes d'estimation ayant une signification fonctionnelle. In: GIANINAZZI, S.; GIANINAZZI-PEARSON, V. (Ed.) Mycorhizes: physiologie et genétique, Dijon: 1986. p.217220.
UOSUKAINEN, M.; VESTBERG, M. Effect of inoculation with arbuscular mycorrhizas on rooting, weaning and subsequent growth of micropropagated Malus (L.) Moench. Agriculture Science in Finland, Helsinki, v.3, p.269-279, 1994.

WRAIGTH, J.M.; WRAIGHT, K.C. Soil water and root growth. HortScience, Alexandria, v. 33, n. 6, p. 951-959, 1998.

ZIV, M. In vitro acclimatization. In: Automation and environmental control in plant tissue culture. Dordresh, Holland: Kluwer Academic Publishers, 1995. 535p. 